\title{
WestVirginiaUniversity
}

THE RESEARCH REPOSITORY @ WVU

Faculty \& Staff Scholarship

$1-24-2022$

\section{DISTANCE RUNNERS IN APPALACHIA: A SURVEY OF INJURIES, TRAINING, AND DIETARY HABITS}

Justine Falcone MD

Sovah Health, justineannefalcone@gmail.com

Katherine Langley MD

Spartanburg Regional Healthcare System, langleykj@gmail.com

Brenden Balcik MD

West Virginia University, bbalcik@hsc.wvu.edu

Rosanna Sikora MD

West Virginia University, rsikora@hsc.wvu.edu

Melinda Sharon MPH

Marshall University, sharon1@marshall.edu

See next page for additional authors

Follow this and additional works at: https://researchrepository.wvu.edu/faculty_publications

Part of the Medical Nutrition Commons, and the Other Medical Sciences Commons

\section{Digital Commons Citation}

Falcone, Justine MD; Langley, Katherine MD; Balcik, Brenden MD; Sikora, Rosanna MD; Sharon, Melinda MPH; and Monseau, Aaron MD, "DISTANCE RUNNERS IN APPALACHIA: A SURVEY OF INJURIES, TRAINING, AND DIETARY HABITS" (2022). Faculty \& Staff Scholarship. 3080.

https://researchrepository.wvu.edu/faculty_publications/3080

This Article is brought to you for free and open access by The Research Repository @ WVU. It has been accepted for inclusion in Faculty \& Staff Scholarship by an authorized administrator of The Research Repository @ WVU. For more information, please contact beau.smith@mail.wvu.edu. 


\section{Authors}

Justine Falcone MD, Katherine Langley MD, Brenden Balcik MD, Rosanna Sikora MD, Melinda Sharon MPH, and Aaron Monseau MD 
DISTANCE RUNNERS IN APPALACHIA: A SURVEY OF INJURIES, TRAINING, AND DIETARY HABITS

Disclaimer: The views expressed in the submitted article are those of the authors and not an official position of the institution or funder.

Word Count: 2973

Number of figures and tables: Four

Conflict of interest declaration: No disclosures.

Keywords: running; injuries; diet; training; Appalachia 


\section{ABSTRACT}

Objectives: The purpose was to examine characteristics of an Appalachian population of runners. The primary aim was to examine risk factors for running related injury (RRI), including mileage per week, experience, and use of applications/training programs. A second aim was to characterize dietary habits among runners. Methods: This study was conducted in September 2015 in North Central Appalachian West Virginia. The Morgantown Marathon consists of three races offered every September: an 8K, half marathon, and full marathon. Surveys were offered to runners ages 18 and older during packet pick-up. For this survey study, questions consisted of multiple choice and openended responses, including demographics, injury history, nutrition habits, and training questions. Results: In September 2015, 444 runners completed the survey. Runners with moderate experience (2-5 years) and running moderate weekly mileage (21-30 miles) had higher RRI. Reported RRI was similar for runners using an app, online program, or local or online coaching (20-29\%). In our study, most runners reported following a balanced diet or eating "whatever". Runners following a vegan diet reported the lowest RRI $(0 \%)$ while those following gluten free diets reported the highest (45\%). Conclusions: Increasing weekly running mileage and use of a training program did not appear to be associated with RRI. Most runners followed a balanced diet or eating "whatever," while those following a vegan diet appeared to have lower reported RRI. Additional larger studies are needed to better characterize these findings and to identify trends in this population.

\section{Word Count (abstract): 242}




\section{INTRODUCTION}

Running remains one of the most popular forms of physical activity among Americans. In 2017, nearly 18.3 million people registered to participate in a running road race. While the $5 \mathrm{~K}$ event (3.1 miles) has had the greatest number of participants with 8.84 million or $49 \%$ of those registered, longer distance events such as the half and full marathon (13.1 and 26.2 miles, respectively) are gaining popularity (1). Running has many well-known health benefits. According to the American College of Cardiology, just 5-10 minutes of running per day can significantly reduce one's risk of cardiovascular death as compared to that of non-runners (2). Likewise, running has many positive mental health benefits including reducing levels of anxiety, depressive symptoms, and frequency of panic $\operatorname{attacks}(3),(4)$.

While there are many well-established health benefits from running, there may be an associated cost of running-related musculoskeletal injuries. Several studies have examined the risk factors for running-related injuries. Saragiotto et al. conducted a systematic review of prospective cohort studies from multiple international databases to examine risk factors for running injury. The study found that the major risk factor for a running related injury (RRI) was previous RRI in the prior 12 months. Additionally, weekly running distance was found to be related to injury; however, the number of miles run and days per week of running varied among studies included in this review (5).

Kemler et al. examined the relationship between use of running applications and RRI, surveying over 1,000 Dutch runners regarding their usage of various running related applications such as Nike+, Runkeeper, and Runtastic. The authors concluded that the use 
of a running application for training did not appear to be associated with a higher or lower rate of RRI. However, it was determined that history of a prior running injury appeared to be a risk factor for a future repeat RRI (6).

To maximize nutritional benefits and minimize the chances of injury, many runners follow specific dietary habits. A study by Turner et al. concluded that $13 \%$ of long distance runners including half-marathon to ultra-distance runners followed a vegetarian or vegan diet, a percentage which is greater than average for the United States. Common reasons reported for following strict dietary habits include performance enhancement, injury prevention, weight loss/maintenance, environmental concerns, and the belief that the particular diet made a runner feel better. While vegetarian and vegan runners must additionally monitor their diets to ensure proper and sufficient nutrient intake, such as iron and vitamin D, runners who do not follow strict regimens may be at risk for consuming lower quality diets, thus hurting their performance and increasing their risk for injury (7).

The relationship between diet and injury in long distance runners may differ based on the geographic location of runners. There is no literature describing characteristics, such as dietary habits and injury risk factors, of runners in the Appalachian region. Therefore, the purpose of the present study was to examine various characteristics of an Appalachian based population of runners. The primary aim was to examine various risk factors for RRI, including running distance per week, running experience, and use of any running applications or training programs. A second aim was to characterize dietary habits among Appalachian runners.

\section{METHODS}


This study was conducted in the North Central Appalachian region of West Virginia. Morgantown, West Virginia is a city with over 30,000 permanent residents and is home to West Virginia University (WVU). The city has a robust running population, with one local running-focused retail store, and frequent running races and events. The Morgantown Marathon Events consist of three races every September and include 8K (5 miles), half marathon (13.1 miles), and full marathon (26.2 miles) events. Runners ages 18 years and older were eligible to participate in the survey. This study was approved by the WVU Institutional Review Board (protocol \#1508804500 on 9/11/15 as exempt protocol).

Surveys were offered to runners during packet pick-up at an expo on the day prior to their event or events. Investigators set up a table at packet pick up for the Morgantown Marathon Events in September 2015. Survey questions consisted of multiple choice and open-ended responses under the categories of Demographics, Race Experience, Training, Nutrition, Injury History, and Additional History. Training questions were focused on assessing different types of training including programs, groups, cross training, stretching, and distance per week. Injury History questions asked runners to report injuries in the past month, year, and while training for their current race event (see Appendix 1). Runners completed the survey on paper and placed their survey in a confidential box upon completion.

Descriptive statistics (i.e. frequencies and percentages) were used to describe quantitative study variables. Open-ended responses including self-report average weekly mileage and description of injury/location were categorized based on responses. Analyses were conducted based on overall counts as well as selected comparisons by race length, 
years of running experience, weekly mileage, type of cross-training, type of training program, and dietary selections.

\section{RESULTS}

A total of 448 runners completed the survey. Four surveys were excluded from the analyses: two did not select a running race category, one was a data entry error, and one was a participant under the age of 18 years. Therefore, the final total for inclusion in the study was 444 runners competing in the three events with 112 in the $8 \mathrm{~K}, 182$ in the half marathon and 167 in the full marathon. The average age of participants was 38.1. The majority of participants in the $8 \mathrm{~K}$ and half marathon were female (72\% and $64 \%$ ) while more men completing the survey participated in the full marathon $(60 \%)$. The largest proportion of runners in the $8 \mathrm{~K}$, half, and full marathon had obtained postgraduate degrees (47.3\%, 41.4\%, and 46.7\%, respectively).

Runners with 2-5 years of running experience were more likely to be recently injured (25\%) as compared to more experienced runners (more than 5 years) or less experienced runners (less than 2 years; Figure 1). Weekly mileage was also compared to injury risk (Figure 2). People who ran moderate amounts of weekly distance (21-30) had higher amounts of injuries (28\%) compared to runners who ran fewer or more weekly miles. However, runners in the higher weekly mileage groups, including 31-40 miles per week and over 40 miles per week, reported the lowest rates of injury (16\% each). 


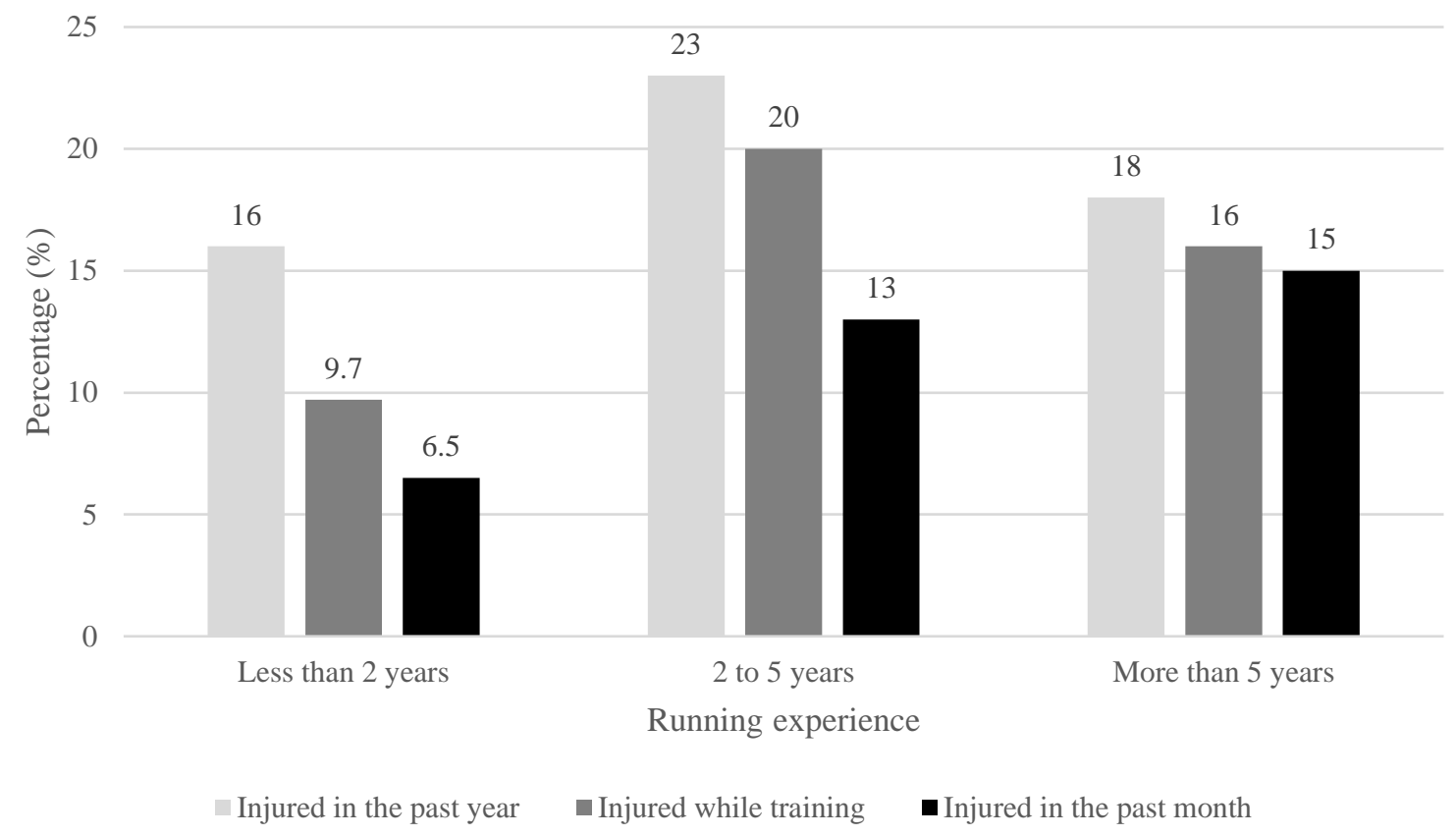

\section{FIGURE 1}

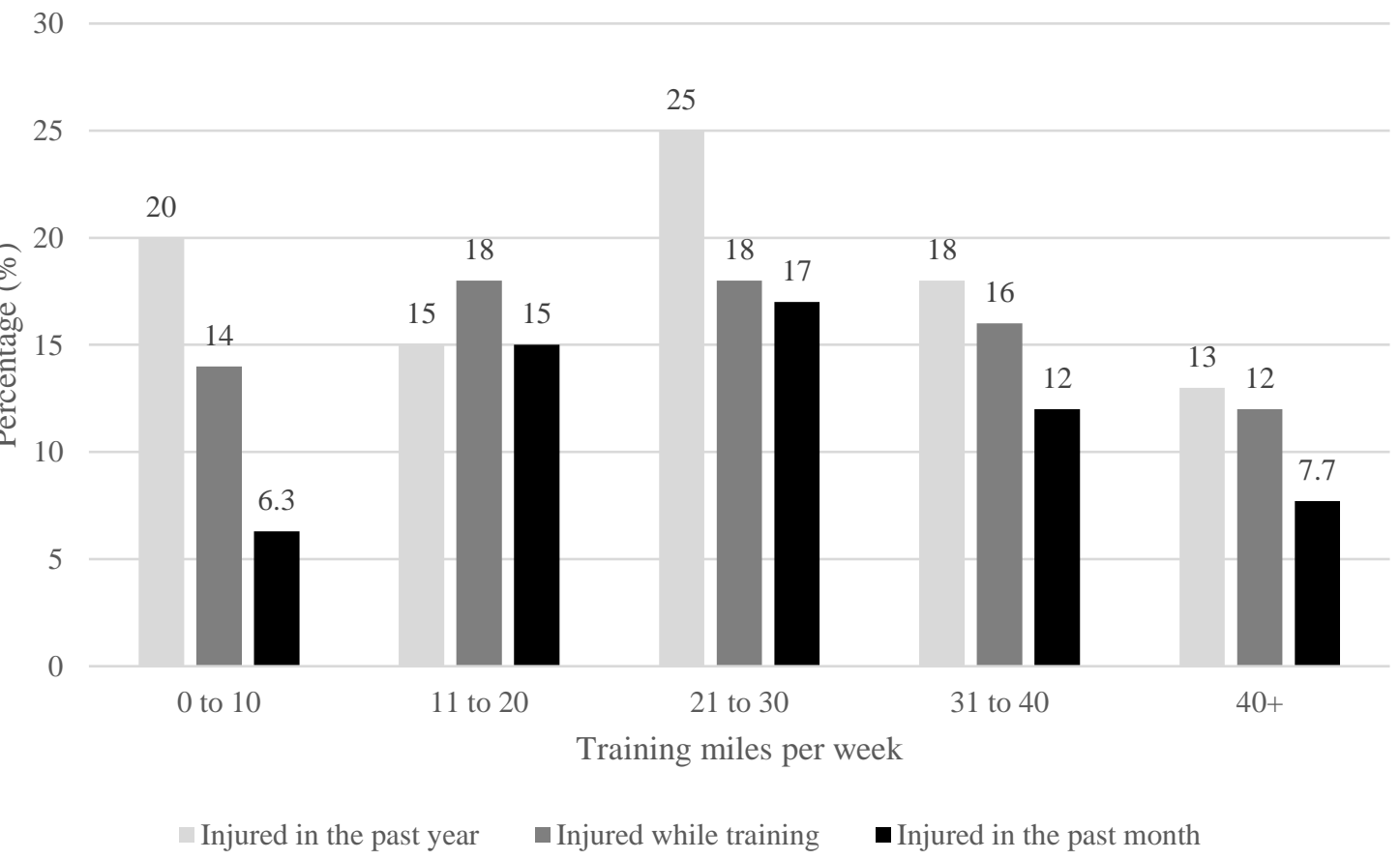




\section{FICURE 2}

Figure 3 demonstrates cross training activities compared to self-reported injury rates. Runners were asked if they participated in cross training events in addition to running including cycling, swimming, rowing, weight training, or team sports. Overall, runners who reported participating in team sports had higher rates of injury with $43 \%$ reporting a recent injury. Athletes participating in swimming as a form of cross training reported the next highest injury rate at $33 \%$. However, athletes in the remaining cross-training events (rowing, weight training, and cycling) reported similar rates of injury (24\%, 25\%, and 28\%, respectively).

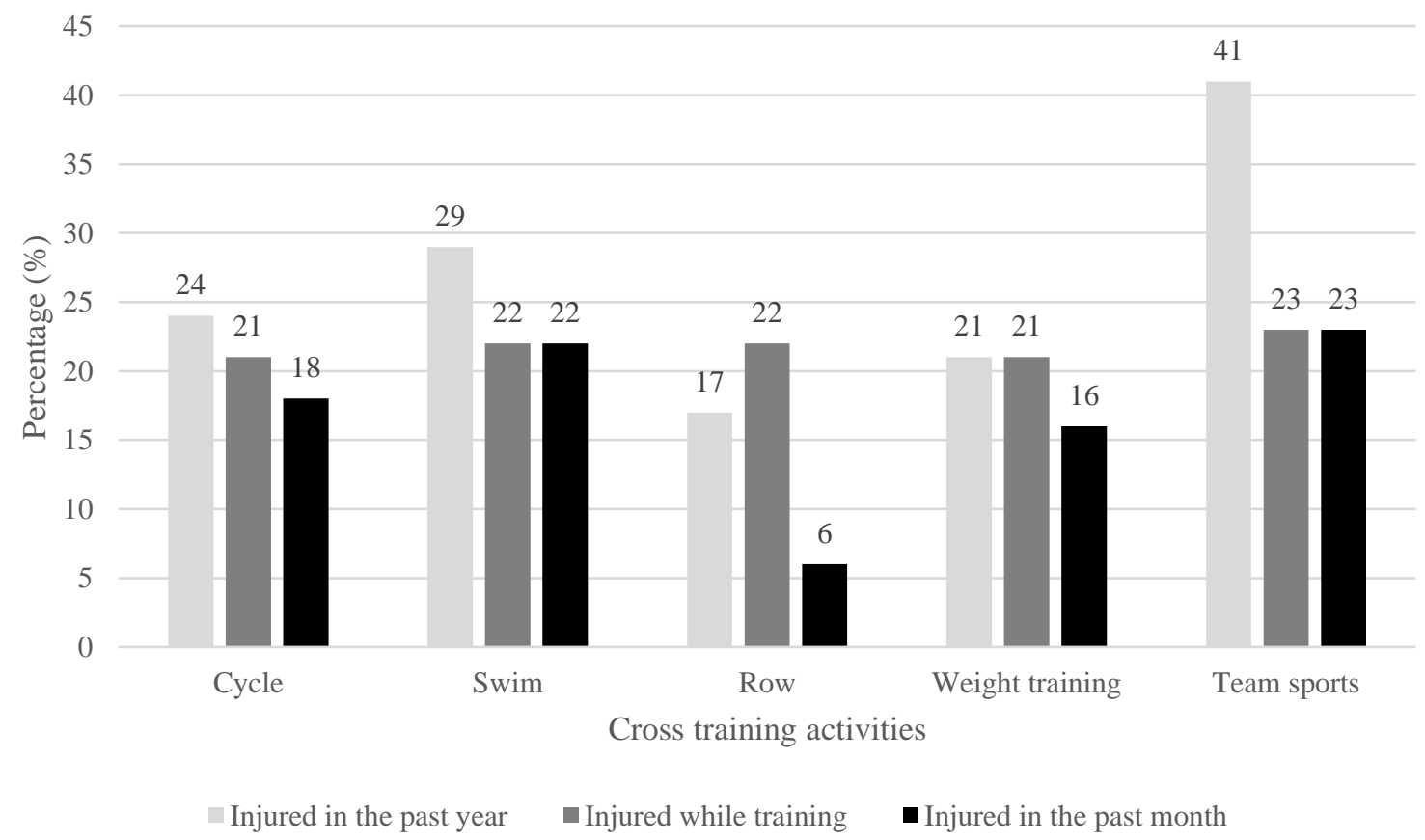

FIGURE 3 
The survey also evaluated whether runners participated in a running-specific training program while training for this event (i.e. online training program, online coaching program, phone application, or local coaching). Of the 14 runners using an online coaching program, four reported an injury before the event (29\%), which is slightly higher than the eight out of 30 runners using an app to train (27\%), 25 of 109 using an online program $(23 \%)$ and seven of 34 using local coaching (21\%).

The athletes participating in the various races reported multiple dietary habits. In general, most athletes in all three events reported either following a balanced diet or "eating whatever." Slightly more runners in the full marathon reported following a vegan diet than runners participating in the half or $8 \mathrm{~K}(2.4 \%, 2.2 \%$, and $0 \%$, respectively). However, more runners reported following a vegetarian diet in the $8 \mathrm{~K}(8 \%)$ than in the half marathon $(5.5 \%)$ or full $(6.6 \%)$. Regarding dietary habits, $45 \%$ of athletes following gluten free diets reported the highest frequency of recent injury (5 of 11). For athletes reporting eating whatever, balanced diets, and vegetarian diets, similar rates of recent injury were reported ( $25 \%$ of $158,24 \%$ of $200,24 \%$ of 29 , respectively). Athletes following a paleo diet (13) reported low rates of recent injury (8\%) while athletes following vegan diets (8) reported the lowest rate of recent injury $(0 \%)$.

\section{DISCUSSION}

To our knowledge, this is the first study to report characteristics of Appalachian distance runners. Given the demographic region of these races, it is not surprising that most participants lived in states in the Appalachian region with the majority of racers in each race residing in West Virginia. Interestingly, as Morgantown is a college town, one may 
have expected a large number of participants to be college students currently working towards their degrees. However, the largest proportion of runners in the $8 \mathrm{~K}$, half, and full marathon held postgraduate degrees.

Several studies have examined risk factors for running related injuries. Saragiotto et al. concluded that the greatest risk for a running related injury (RRI) was previous RRI in the past 12 months, while Van der Worp et al. also reported previous injury as a risk factor for RRI (5) (8). Additionally, Saragiotto et al. noted that higher weekly running distance was found to be related to injury but the amount of weekly running varied among the included studies (5). Interestingly, in the present study, participants running moderate amounts of distances (21-30 miles per week) appeared to have more RRI than runners covering more or less weekly distance. In particular, runners in the highest weekly mileage groups (31-40 and 40+ miles per week) reported the lowest RRI. On the other hand, the lowest mileage group, 0-10 miles/week, had the second highest rate of injury. Therefore, this data does not suggest a direct correlation between injury risk and increasing weekly mileage as has been suggested by Saragiotto et al. and other studies (4) (9).

It is possible that the runners completing higher weekly mileage may have more experience in the sport, and therefore, these runners may be more knowledgeable about injury avoidance. Prior experiences may play a role in appropriate self-care such as massage, need for physical therapy or simply scheduling a day off in order to avoid injury. Another explanation is that injured runners are not able to train as much. Kemler et al. concluded that novice runners (running $<1$ year) reported more injuries compared to experienced runners, and similarly, Linton et al. noted that more experienced runners had 
lower rates of injury (9) (10). Our data suggest that more experienced runners (running >5 years) had somewhat lower rates of injury as compared to less experienced runners (2-5 years' experience), but higher rates of injury compared to the most inexperienced runners (less than 2 years' experience). Further studies are needed to better characterize the association between RRI and weekly mileage as compared to running experience.

Runners are known for participating in other sports for a variety of reasons. An often-cited reason for participating in cross-training activities, such as weight training, cycling, or swimming, is for injury prevention. Several studies have examined the relationship between sports specialization and risk of injury. Bell et al performed a systematic review and found that sports specialization was associated with a higher risk of musculoskeletal related injuries (11). On the other hand, Sugimoto et al. found that single versus multiple sport participation did not pose a significant injury risk but rather increased training volume contributed to greater likelihood of injury (12). Unlike our population, data from these studies included athletes exclusively under the age of 18 . While our data included adult runners age 18 and older, we found that about half the runners participated in some form of cross-training activity. Our data suggest that athletes participating in team sports as a form of cross training experienced the highest rates of injury. This observation could be related to the contact aspect of many team sports. Runners who also participated in swimming reported somewhat higher amounts of RRI than those participating in the remaining cross training activities, all of whom reported similar rates of RRI. As a survey study, we may have simply demonstrated that injured runners choose to swim to prevent 
further injury. Further studies are needed to better characterize the relationship between cross-training and injury prevention, particularly in an adult population.

About $38 \%$ of survey participants reported using some form of training program such as online program, online coaching, an app, or local coaching. Based on the survey method used to obtain the study data, participants were not able to elaborate on what type of online program or app they were using to train. Kemler et al. found that use of a running application did not appear to be associated with a higher or lower rate of running injury (6). Similarly, in the present study, when compared to the other forms of training programs, use of an app did not appear to be associated with more or less frequent RRI. Using an online coaching program was associated with the highest reported injury while use of a local coach was associated with the lowest. The reason for such trends is unclear but could possibly be due to more personalized training strategizes provided by a local- in personcoach rather than by a remote online coach or use of a generic application.

It is well known that some runners follow specific dietary practices for various reasons such as to enhance their performance, reduce injury risk, or promote weight loss (7). Prior literature has reported that longer distance runners are more likely to follow a vegetarian or vegan diet, as compared to the average American (7). Our data showed that most runners reported following a balanced diet or eating whatever including those in the 8K to full marathon distance. In particular, our data did not show a clear association between vegetarian or vegan dietary habits and longer distance running. A slightly higher percentage of runners participating in the full marathon reported following a vegan diet 
$(2.4 \%)$ compared to those in the half marathon $(2.2 \%)$ or $8 \mathrm{~K}(0 \%)$, but similar trends were not seen for runners reporting a vegetarian diet.

A commonly cited reason for following a particular dietary habit such as vegetarian or vegan is for injury prevention (7). While the majority of the runners in our study reported following a balanced diet or eating whatever, this choice was not found to be associated with the highest rates of injury. Interestingly, those runners who reported following a gluten or dairy free diet tended to report the most injuries. Runners following a gluten free diet appeared to have the highest rates of injury with nearly $45 \%$ reporting an injury. While following a vegetarian diet did not seem to be injury protective, as $24 \%$ of athletes reported an injury, following a vegan diet did appear to be associated with a lower rate of injury as $0 \%$ of these runners reported an RRI. It is possible that certain dietary practices may be associated with lower risk of injury. However, further studies with larger populations and inclusion of runners from other regions of the country are needed to better characterize these findings.

Our study has a number of limitations to consider. First, utilizing a survey for data collection is requiring participants to select from a subset of preformed answer choices. Although our survey was generated specifically for this study and was not validated, it was modeled after prior work from Hølmich et al. and van Middelkoop et al., studying general demographics of marathon participants as well as training mileage and associated lower extremity injury in the Danish and Dutch populations, respectively (13) (14). As a result of this format, runners' answers are limited to the available choices, thus not allowing them to expand upon certain answer choices when necessary. Participants were asked to report 
injury occurrence in the past month, past year, and while training for the event. About 37 participants provided inconsistent responses towards being injured in the past year and in the month prior to the event. Therefore, the 37 participants reporting inconsistent responses were removed and a "recent injury" dependent variable was created. A recent injury was considered as a yes if the participant responded with a yes to at least one of the three injury related questions.

Another notable limitation was that some runners competed in both the $8 \mathrm{~K}$ plus the half or full marathon, because the events were held on different days in the inaugural year. Therefore, the ability to draw conclusions about runners competing in shorter (8k) events compared to longer distance (full marathon) events may be limited. Additionally, this was a single-location race event weekend, with the majority of runners living locally to the race location. Lastly, when asked about diet, some participants selected more than one answer for their dietary practice. Therefore, it cannot be determined if someone reporting a specific diet truly followed this regimen consistently.

\section{CONCLUSION}

This study was the first to analyze characteristics of an Appalachian population of runners. Our data did not suggest an association between increased risk of injury and increasing weekly mileage as has been proposed by other studies. Furthermore, when comparing use of an app, online program, or coaching, there did not appear to be a substantial injury prevention benefit from one program over another. Other studies have shown that distance runners are more likely to follow a vegetarian or vegan diet, which may be associated with injury prevention. However, in our study, most runners, regardless of 
distance, reported following a balanced diet or eating whatever. Our data did suggest that in the small number of those runners following a vegan diet, there appeared to be an injury prevention benefit. Future research, as well as analyses of subsequent year races, are needed to better characterize these findings on a larger scale, and to identify trends in this population of runners.

ACKNOWLEDGEMENTS: Special thanks to Makenzy Sufficool for help with data processing.

\section{References}

1. U.S. Road Race Participation Numbers Hold Steady for 2017. Running USA. Accessed November 1, 2018.

https://runningusa.org/RUSA/News/2018/U.S._Road_Race_Participation_Numbers_Hold_Steady_ for_2017.aspx

2. Napoli N. Running Reduces Risk of Death Regardless of Duration, Speed. The American College of Cardiology Accessed November 1, 2018. https://www.acc.org/about-acc/pressreleases/2014/07/29/09/32/leisure-running-jacc-pr

3. Anderson E, Shivakumar G. Effects of exercise and physical activity on anxiety. Front Psychiatry. 2013;4:27. doi:10.3389/fpsyt.2013.00027

4. Ströhle A, Graetz B, Scheel M, et al. The acute antipanic and anxiolytic activity of aerobic exercise in patients with panic disorder and healthy control subjects. J Psychiatr Res. Aug 2009;43(12):1013-7. doi:10.1016/j.jpsychires.2009.02.004

5. Saragiotto BT, Yamato TP, Junior LCH, Rainbow MJ, Davis IS, Lopes AD. What are the main risk factors for running-related injuries? Sports medicine. 2014;44(8):1153-1163.

6. Kemler E, Romeijn K, Vriend I, Huisstede B. The relationship between the use of running applications and running-related injuries. Phys Sportsmed. 02 2018;46(1):73-77.

doi:10.1080/00913847.2018.1412812 
7. Turner-McGrievy GM, Moore WJ, Barr-Anderson D. The Interconnectedness of Diet Choice and Distance Running: Results of the Research Understanding the NutritioN of Endurance Runners (RUNNER) Study. Int J Sport Nutr Exerc Metab. 06 2016;26(3):205-211. doi:10.1123/ijsnem.20150085

8. Van der Worp MP, Ten Haaf DSM, van Cingel R, de Wijer A, Nijhuis-van der Sanden MWG, Staal JB. Injuries in runners; a systematic review on risk factors and sex differences. PLoS One. 2015;10(2):e0114937.

9. Kemler E, Blokland D, Backx F, Huisstede B. Differences in injury risk and characteristics of injuries between novice and experienced runners over a 4-year period. Phys Sportsmed. 11 2018;46(4):485-491. doi:10.1080/00913847.2018.1507410

10. Linton L, Valentin S. Running with injury: A study of UK novice and recreational runners and factors associated with running related injury. J Sci Med Sport. Dec 2018;21(12):1221-1225. doi:10.1016/j.jsams.2018.05.021

11. Bell DR, Post EG, Biese K, Bay C, Valovich McLeod T. Sport Specialization and Risk of Overuse Injuries: A Systematic Review With Meta-analysis. Pediatrics. 09 2018;142(3)doi:10.1542/peds.2018-0657

12. Sugimoto D, Jackson SS, Howell DR, Meehan WP, Stracciolini A. Association between training volume and lower extremity overuse injuries in young female athletes: implications for early sports specialization. Phys Sportsmed. May 2019;47(2):199-204.

doi:10.1080/00913847.2018.1546107

13. Hølmich $\mathrm{P}, \mathrm{Christensen} \mathrm{SW,} \mathrm{Darre} \mathrm{E,} \mathrm{Jahnsen} \mathrm{F,} \mathrm{Hartvig} \mathrm{T.} \mathrm{Non-elite} \mathrm{marathon} \mathrm{runners:}$ health, training and injuries. Br J Sports Med. Sep 1989;23(3):177-8. doi:10.1136/bjsm.23.3.177

14. van Middelkoop M, Kolkman J, van Ochten J, Bierma-Zeinstra SM, Koes BW. Course and predicting factors of lower-extremity injuries after running a marathon. Clin J Sport Med. Jan 2007;17(1):25-30. doi:10.1097/JSM.0b013e3180305e4d

Appendix 1 
Please mark box for your response or fill in the blank where appropriate.

Race: $\square$ 8k $\quad \square$ Half $\quad \square$ Marathon

Demographics:

Gender: $\square \mathrm{M} \quad \square$ FAge: __ $\quad \mathrm{Ht}: \_$Wt: __ lbs

State of Residence:

Highest Education completed:

$\square 8^{\text {th }}$ grade $\square$ High School diploma/GED $\square$ Some college $\square$ Associate degree

$\square$ Bachelor's degree $\square$ Postgraduate degree

$\underline{\text { Race Experience: }}$

Number of Races completed prior: ___ $5 \mathrm{~K} \_$__ $8 \mathrm{k} \_$Half __ Marathon

Number of years running: $\square$ Less than $2 \quad \square 2-5 \quad \square$ greater than 5

Have you ever qualified for the Boston Marathon? $\square \mathrm{Y} \quad \square \mathrm{N}$

Training:

Did you follow a specific training program? $\square \mathrm{Y} \quad \square \mathrm{N}$

If so, what type of program?

$\square$ Online program $\square$ Online coaching $\quad \square$ App $\quad \square$ Local coaching 
Did you train with a group? $\quad \square \mathrm{Y} \quad \square \mathrm{N}$

Average weekly distance (in miles)

Average weekly hours? $\quad \square$ Less than $3 \quad \square 4-6 \quad \square$ greater than 6

Average weekly days per week? $\square 3-4 \quad \square 5-6 \quad \square$ daily

Did you do interval training? $\quad \square \mathrm{Y} \quad \square \mathrm{N}$

Did you do distance training? $\quad \square \mathrm{Y} \quad \square \mathrm{N}$

What surface did you train on? $\square$ Hard ground/asphalt $\square$ gravel $\square$ treadmill

Longest distance prior to event? (miles)

Longest distance was run weeks prior to event

Do you cross train? $\square \mathrm{Y} \quad \square \mathrm{N}$

If so, what activities?

$\square$ Cycle $\quad \square$ Swim $\quad \square$ Row $\quad \square$ Weight training $\quad \square$ Team Sports

Do you participate in weight training? $\square \mathrm{Y} \quad \square \mathrm{N}$

Do you stretch prior to running? $\quad \square \mathrm{Y} \quad \square \mathrm{N}$

Do you stretch after running? $\quad \square \mathrm{Y} \quad \square \mathrm{N}$

Do you alternate running shoes? $\quad \square \mathrm{Y} \quad \square \mathrm{N}$ 
Nutrition:

Do you use supplements? $\square \mathrm{Y} \quad \square \mathrm{N}$

Do you take vitamins? $\square \mathrm{Y} \quad \square \mathrm{N}$

How would you describe your diet?

$\square$ Paleo $\quad \square$ Vegan $\quad \square$ Vegetarian $\quad \square$ Gluten free $\quad \square$ Dairy free $\quad \square$ Balanced $\square$ I eat whatever I want

Did you change your diet prior to event? $\square \mathrm{Y} \quad \square \mathrm{N}$

If so, did you increase you carbohydrate intake? $\square \mathrm{Y} \quad \square \mathrm{N}$

Injury history:

Have you experienced a musculoskeletal injury in last year? $\quad \square \mathrm{Y} \quad \square \mathrm{N}$

Were you injured while training for this event? $\square \mathrm{Y} \quad \square \mathrm{N}$

Were you injured in the last month? $\square \mathrm{Y} \quad \square \mathrm{N}$

If yes, did the injury keep you from training? $\square \mathrm{Y} \quad \square \mathrm{N}$

Please describe injury/location:

Hip

Groin

Thigh/Quad

Hamstring

Knee

Calf

Shin Achilles

Ankle

Foot

Toe 
Additional History:

Daily Smoker? $\square \mathrm{Y} \quad \square \mathrm{N}$

Alcohol use? $\square \mathrm{Y} \quad \square \mathrm{N}$

Medical problems: $\square$ Diabetes $\square$ High blood pressure $\square$ High cholesterol

$\square$ Coronary artery disease $\quad \square$ Asthma $\quad \square$ Thyroid problem $\quad$ Other (list below): 